\title{
Experimental and numerical investigations on the combustion and emission characteristics of an ethanol/diesel dual-fuel engine
}

\author{
Shijun Dong ${ }^{a}$, Xiaobei Cheng ${ }^{b}$ and Biao Ou ${ }^{c}$ \\ School of Energy and Power Engineering, Huazhong University of Sci. \& Tech., Wuhan, China \\ adongshijun@hust.edu.cn, ${ }^{b}$ chengxiaobei@sina.com, ${ }^{c}$ ou_biao@sina.com
}

Keywords: ethanol/diesel; simulation; combustion; emission; cyclic variation;

Abstract. Experiments and simulations were conducted to investigate the combustion and emission characteristics of ethanol/diesel dual-fuel combustion. The experiments were performed on a light-duty diesel engine with direct injection of diesel combined with port injection of ethanol. The results showed that the ethanol/diesel dual-fuel mode could reduce soot and NOx emissions simultaneously without EGR even at the higher load. However, the UHC and CO emissions of the ethanol/diesel dual-fuel mode increased gradually with the increase of ethanol proportion. Simulations showed that high UHC and $\mathrm{CO}$ emissions were formed in the crevice regions as well as cylinder center due to the lower reactivity of ethanol. It was also found that the cyclic variations of the ethanol/diesel dual-fuel mode increased gradually with the increase of premixed ratio at both loads. This was mainly due to the lower reactivity of ethanol.

\section{Introduction}

Diesel engines are widely used for transportation and power generation applications because of their high fuel efficiency. However, diesel engines can cause environmental pollution due to their high soot and NOx emissions. In order to further reduce diesel engine emissions to meet the stringent emission regulations in the future, researchers have put forward many advanced combustion strategies. Most of these combustion strategies can be placed into the category of Premixed Compression Ignition Low Temperature Combustion (PCI-LTC). Many studies have confirmed that these combustion strategies can simultaneously reduce soot and NOx emissions while maintaining equivalent thermal efficiency with diesel engines [1]-[3]. However, most PCI strategies present the challenge in ignition timing and heat release rate control since the ignition and injection events become decoupled and the combustion rate is no longer limited by the mixing process. To meet these challenges, researchers have proposed the concept of dual-fuel PCI combustion, such as Reactivity Controlled Compression Ignition (RCCI) [4]-[7]. Many studies have shown that dual-fuel PCI can simultaneously reduce soot and NOx with good control of heat release rate [8]-[12].

Ethanol is usually used as port injected fuel in dual-fuel PCI studies because of its low reactivity. Studies have shown that dual-fuel PCI combustion with ethanol premixed, ultra-low soot and NOx emissions can be realized with nearly $60 \%$ indicated thermal efficiency [9]-[14]. It is also found that dual fuel engines are often observed with large cyclic variations. Since cyclic variations of combustion dramatically affect engine emissions and efficiency, investigation of cyclic variations in dual-fuel modes has attracted increasing attention in recent years [15]-[17].

In this study, experiments and simulations were conducted to investigate the combustion processes of ethanol/diesel dual-fuel operation. The variation of indicated mean effective pressure (IMEP) was used to quantify cycle-by-cycle variations.

\section{Experimental setup}

The experiments were performed on a single-cylinder, naturally aspirated light-duty diesel engine as shown in Fig. 1. The main engine specifications are listed in Table 1. In this study, ethanol was injected into the intake manifold and diesel was direct injected into the cylinder. The fuel properties of diesel and ethanol used in this study are listed in Table 2. The port fuel injection timing and injected fuel mass 
was controlled by an electronic control unit (ECU) independent of the diesel engine. The port fuel injection pressure was maintained at 5 bar with the injection timing of $297^{\circ} \mathrm{CA}$ BTDC (while the intake valve was open). And diesel was direct injected into the cylinder with a cone angle of $154^{\circ}$. The direct injection timing was kept constant at $25^{\circ} \mathrm{CA}$ BTDC to obtain appropriate combustion phasing and the injected pressure was maintained at $20 \mathrm{MPa}$. The specifications of the port and direct injection system are listed in Table 3.

Table 1. Engine specifications.

\begin{tabular}{|c|c|}
\hline Bore $\times$ stroke & $105 \times 115 \mathrm{~mm}$ \\
\hline Displacement & $0.996 \mathrm{~L}$ \\
\hline Connecting road length & $190 \mathrm{~mm}$ \\
\hline Number of valves & 2 \\
\hline Geometry compression ratio & $18.0: 1$ \\
\hline Combustion chamber & Bowl in piston \\
\hline Intake valve open timing* & $-391^{\circ} \mathrm{CA}$ ATDC \\
\hline Intake valve close timing* & $-108^{\circ} \mathrm{CA}$ ATDC \\
\hline Exhaust valve open timing* & $111^{\circ} \mathrm{CA}$ ATDC \\
\hline Exhaust valve close timing* & $343^{\circ} \mathrm{CA}$ ATDC \\
\hline
\end{tabular}

$* 0{ }^{\circ} \mathrm{CA}$ is the top dead center of the compression stroke.

Table 2. Fuel properties of diesel and ethanol.

\begin{tabular}{|c|c|c|}
\hline & Diesel & Ethanol \\
\hline Molecular formula & C12-C25 & C2H5OH \\
\hline Research octane number (RON) & 25 & 107 \\
\hline Oxygen content (wt. \%) & 0 & 34.8 \\
\hline Density (g/ml) & $0.84-0.88$ & 0.785 \\
\hline Lower heating value (MJ/kg) & 42.5 & 26.8 \\
\hline Stoichiometric ratio & 14.5 & 9 \\
\hline Heat of evaporation (kJ/kg) & 0.27 & 0.84 \\
\hline
\end{tabular}

Table 3. Specifications of port and direct injection systems.

\begin{tabular}{|l|l|l|}
\hline Port-injector & Steady flow rate @ 5 bar & $4.24 \mathrm{ml} / \mathrm{s}$ \\
\hline & Injection pressure & $5 \mathrm{bar}$ \\
\hline Direct-injector & Number of holes & 5 \\
\hline & Included spray angle & $154^{\circ}$ \\
\hline & Nozzle diameter & $0.28 \mathrm{~mm}$ \\
\hline
\end{tabular}

The in-cylinder pressure was measured by a Kistler model 6125B pressure transducer in conjunction with a Kistler model 6125B charge amplifier. The Top Dead Center (TDC) was measured by an Optical Encoder. In-cylinder pressures of 200 consecutive cycles were recorded with a resolution of $0.1^{\circ} \mathrm{CA}$ for combustion analysis at each operating case. To assess the stability of the engine operating condition, the Coefficient of Variation (COV) of IMEP and $Q_{f}$ were used in this study. The COV of 
IMEP was defined as the ratio of the standard deviation over the mean of the IMEP and can be calculated with the cycle cylinder pressure. The COV of $Q_{f}$ was defined as the ratio of the standard deviation over the mean of the $Q_{f}$ and can be calculated based on the cycle cylinder pressure. The exhaust gas composition of CO, UHC (unburned hydrocarbon), and NOx emissions were measured by a gas analyzer (HORIBA 584L). The smoke opacity was measured by a smoke meter (AVL DiSmoke 4000).

The test conditions are listed in Table 4. In this study, all the tests were conducted at engine speed of $1700 \mathrm{r} / \mathrm{min}$. EGR was not used for all the test conditions. The cooling water and lubricating oil temperature were kept at $70 \pm 2^{\circ} \mathrm{C}$ and $90 \pm 2^{\circ} \mathrm{C}$, respectively. At each tested condition, the engine was run for about half an hour until the engine parameters were stable. Then the results of in-cylinder pressures and emissions were recorded.

In this study the premixed ratio $\left(r_{e}\right)$ was defined as the ratio of cycle energy of ethanol to total energy which included port fuel and directly injected fuel. $\square_{p}$ was defined as the equivalence ratio of the charge when the intake valve was closed.

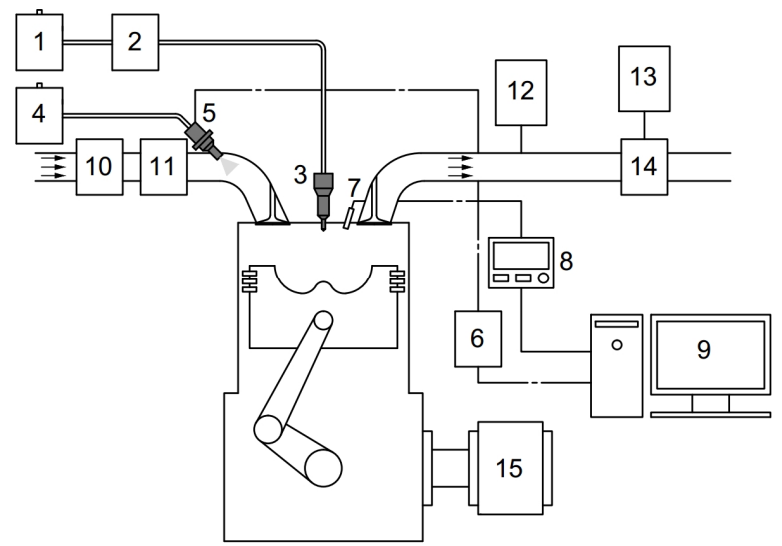

Fig.1. Engine setup. 1. Diesel tank; 2. Diesel consumption meter; 3. Diesel injector; 4. Port fuel tank; 5. Port fuel injector; 6. Port fuel ECU; 7. Pressure transducer; 8. Charge amplifier; 9. Computer; 10. Intake air flow meter; 11. Intake surge tank; 12. Smoke meter; 13. Exhaust analyzer; 14. Exhaust surge tank; 15. Dynamometer;

\section{Computational Simulation}

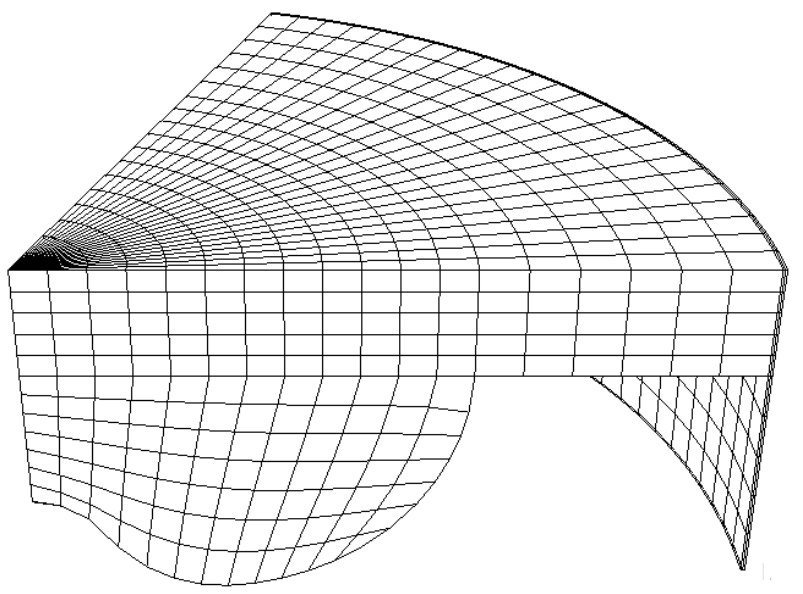

Fig.2. The computational mesh with crevice volume at $-20^{\circ} \mathrm{CA}$ ATDC.

The simulations were conducted using the multi-dimensional simulation code, KIVA-3v release 2 coupled with the CHEMKIN II solver. The spray model employed in this study uses the Lagrangian Drop and Eulerian-Fluid (LDEF) approach. The hybrid Kelvin Helmholtz (KH) - Rayleigh Taylor (RT) model was used to model the droplet breakup. The re-normalization group (RNG) k-EError! Reference source not found. turbulence model was employed to model the in-cylinder turbulence. As 
shown in Fig. 2, the three dimensional computational grid with crevice volume was resolved. The 72 degree sector meshes with periodic boundaries were employed. A reduced mechanism with 48 species and 167 reactions was employed for n-heptane and ethanol chemistry simulation in the present study.
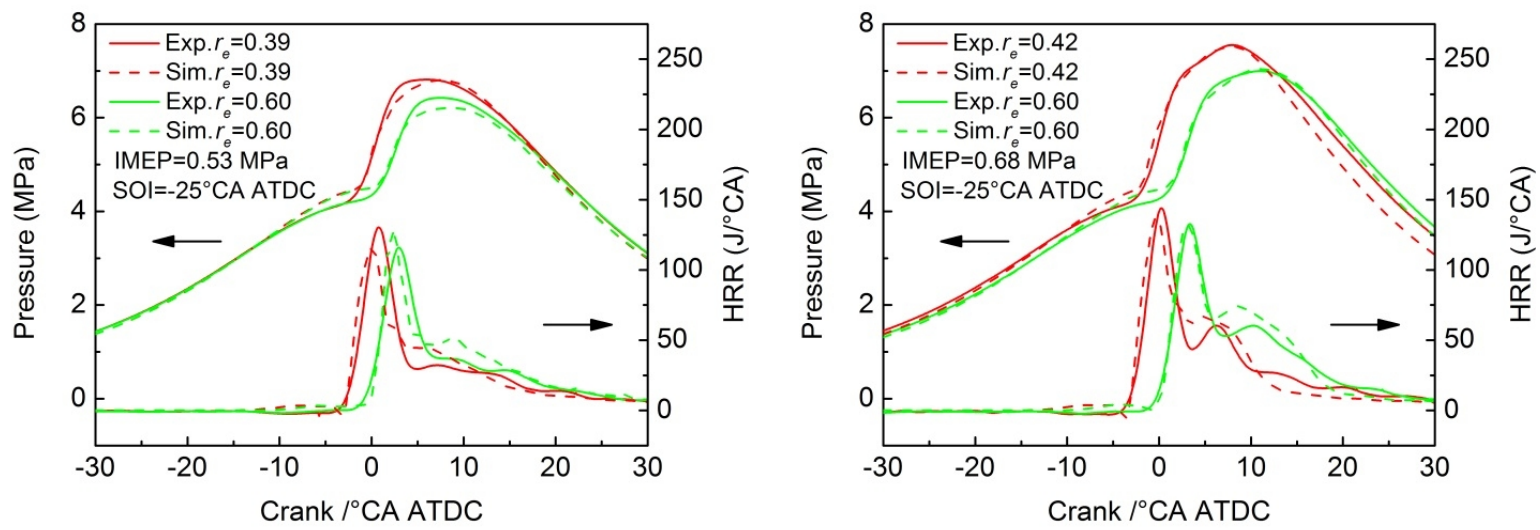

Fig.3. The experimental and simulated in-cylinder pressure and HRR.

Fig. 3 illustrates the comparisons of experimental and simulated pressure and heat release rate (HRR) for both engine loads. As shown in Fig. 3, the simulated results, including the ignition delay, combustion phasing and peak pressure, agree well with experimental results. Therefore, the simulation is considered valid for investigating the ethanol/diesel dual-fuel combustion process.

\section{Results and Discussion}

\section{Effects of premixed ratios on in-cylinder pressure and HRR}

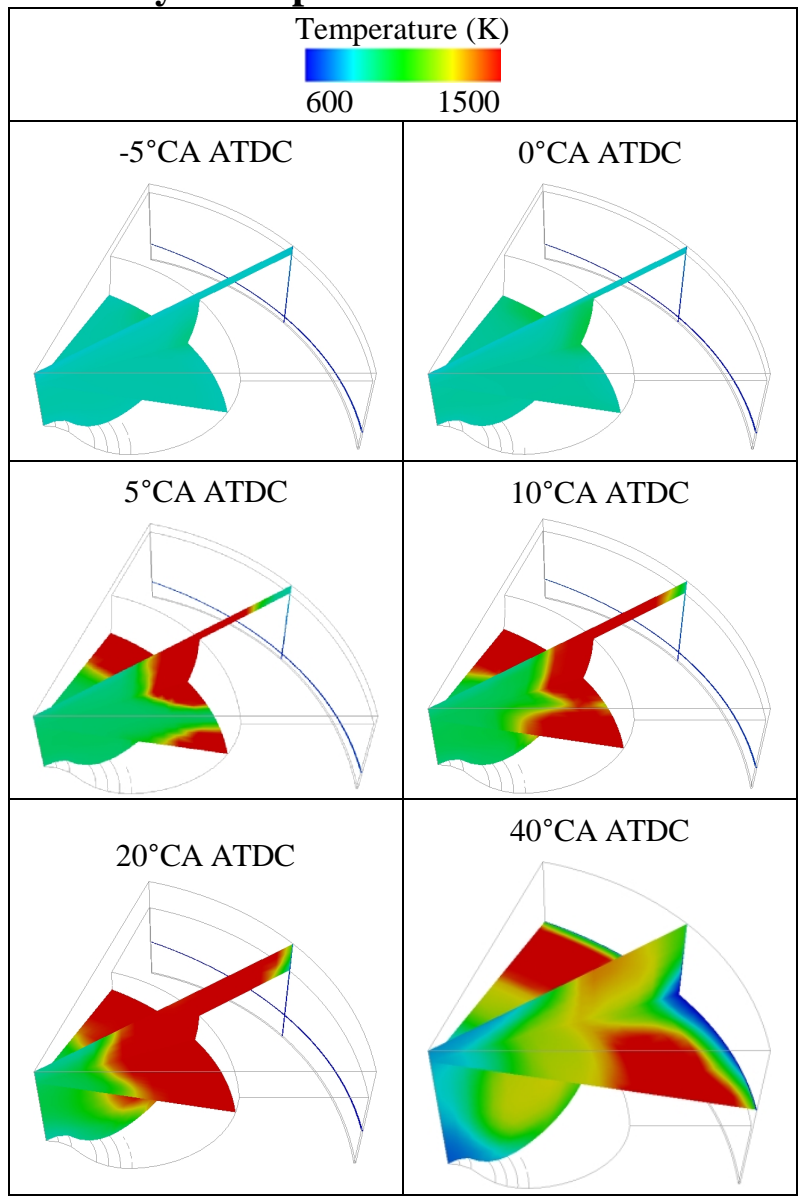

Fig.4. Combustion process of ethanol/diesel case at 0.53 MPa IMEP. The premixed ratio is 0.60.

Fig.4 illustrates the combustion process of the two dual-fuel modes. It can be seen that the mixtures 
along the bowl lip ignited first due to higher reactivity, and then the reaction zone proceeded gradually toward the cylinder wall and cylinder center.
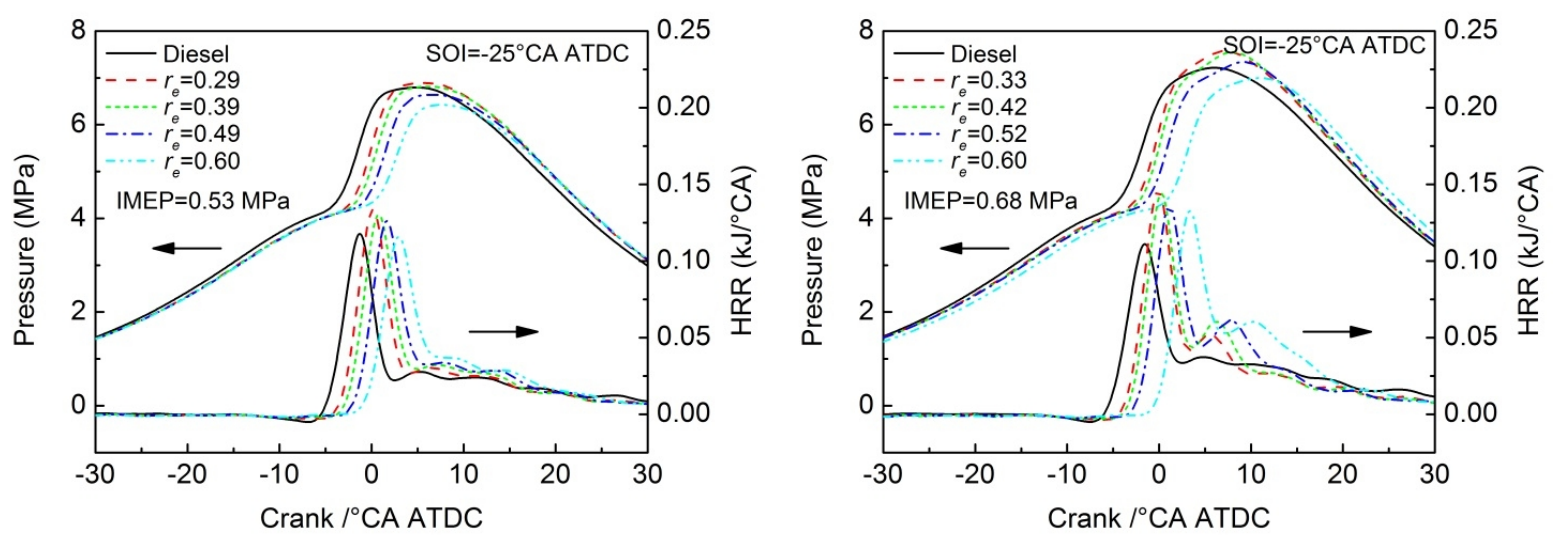

Fig.5. Experimental in-cylinder pressure and HRR, the start of injection (SOI) is $-25^{\circ} \mathrm{CA}$ ATDC.

As can be seen from Fig.5, the ignition delay of ethanol/diesel mode increased significantly with increasing premixed ratio. This is mainly due to the lower reactivity of ethanol which slowed down the reaction of diesel. Additionally the higher enthalpy of vaporization of ethanol reduced the gas temperature. Thus these factors leaded to longer ignition delay with premixed ethanol, and this was consistent with previous studies [13].At 0.53 MPa IMEP, the peak pressure and HRR first increased and then decreased with the increase of ethanol proportion. The increase of peak pressure is mainly due to the longer ignition delay which resulted in more well premixed mixtures before ignition. When the proportion of ethanol was further increased, the reactivity of mixtures was decreased and the ignition was retarded after top dead center. Additionally, the amount of diesel was greatly reduced which resulted in less heat release in first stage of combustion. Thus the peak HRR was reduced with further increase of ethanol. At $0.68 \mathrm{MPa}$ IMEP, the combustion phasing was retarded and a significant two-stage HRR was observed with increasing ethanol proportions.

\section{Effects of premixed ratios on emissions}
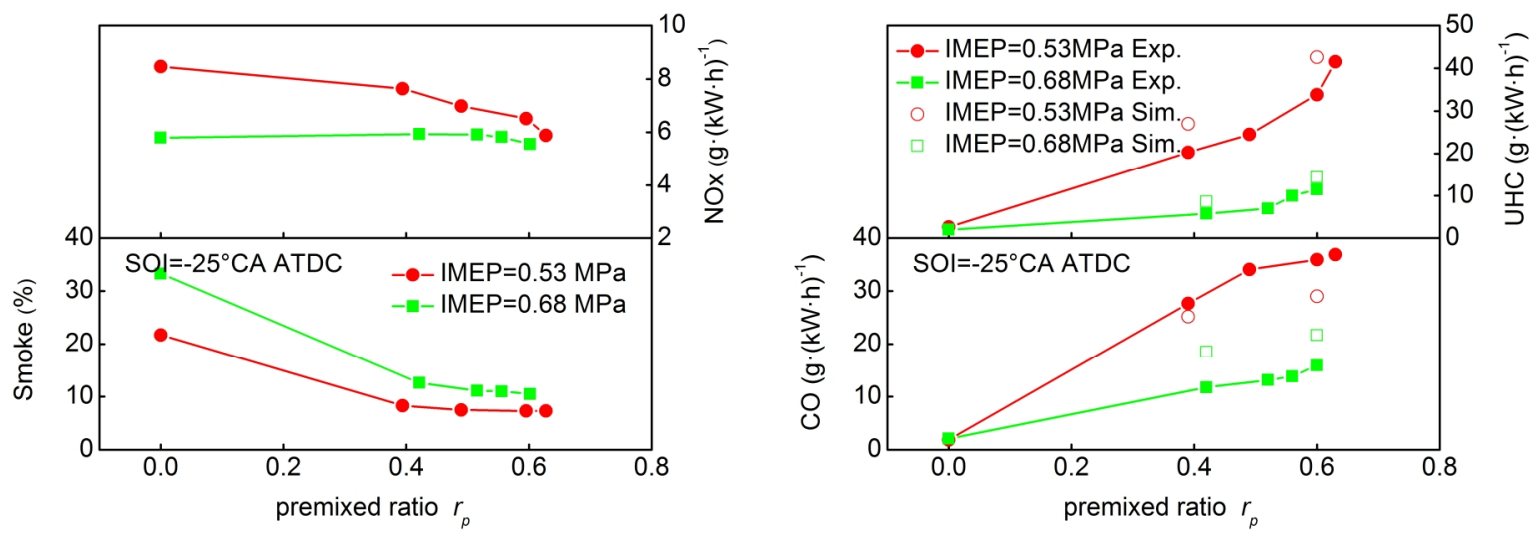

Fig. 6. Comparison between the measured and simulated emissions.

Fig. 6 illustrates emissions with various premixed ratios under different loads. As can be seen, the NOx trends were consistent with the trends of peak cylinder pressure. The soot emissions of both dual fuel modes decreased gradually with the increase of port fuel. This is mainly due to the reduction of direct injected diesel combined with increase of ethanol, which results in larger proportion of premixed combustion and reduced rich regions in the combustion chamber. The results showed that soot emission of dual-fuel combustion was mainly determined by proportions of port fuel. 
The quenching effect of mixtures near wall and crevice regions is the major source of UHC and CO emissions [12]. As can be seen from Fig.5, the UHC and CO emissions increased gradually with increasing proportions of port fuel under both loads. The UHC and $\mathrm{CO}$ emissions were significantly reduced at the higher loads. At the higher load, the increased combustion and boundary temperature could enhance the oxidation of UHC and CO. Thus the UHC and CO emissions were significantly reduced at the higher loads. Fig.5 also illustrates the comparisons of simulated and experimental results of UHC and CO emissions. UHC was significantly over-predicted for ethanol/diesel case. And CO was under-predicted for both dual-fuel modes. However, the magnitudes of UHC and CO emissions for both dual-fuel modes were well captured by numerical simulations.

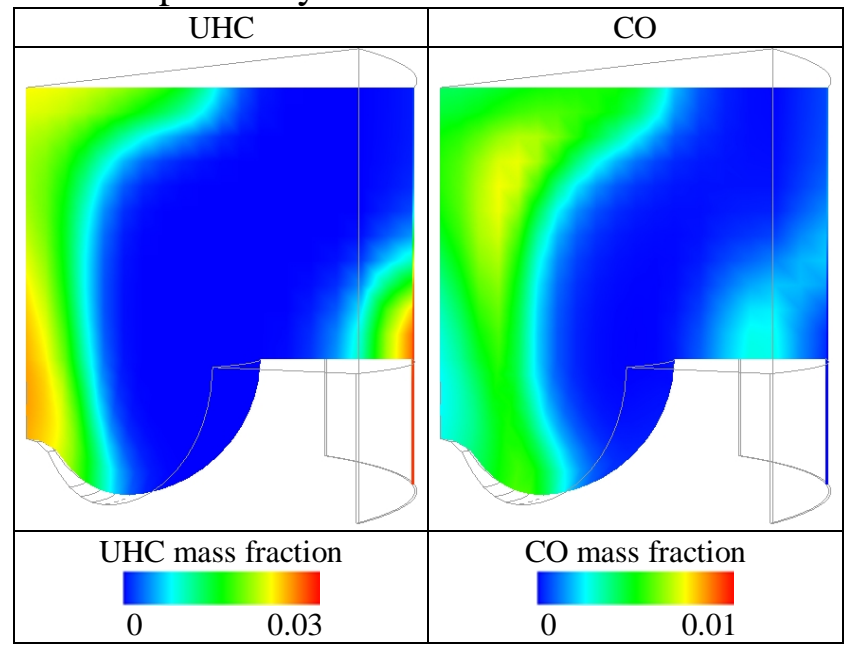

Fig. 7. UHC and CO mass fractions for $0.53 \mathrm{MPa}$ IMEP with ethanol proportion of 0.60 . The results are shown at $60^{\circ} \mathrm{CA}$ ATDC.

As can be seen from Fig.7, large amount of UHC was observed in the cylinder center region. The results showed that at $0.53 \mathrm{MPa}$ IMEP the UHC and CO emissions were mainly distributed in the cylinder center and crevice regions. Walton et al. [19] and Curran et al. [20] have found that the equivalence ratio of the iso-octane ignition limit is about 0.2 , where at equivalence ratios of $\sim 0.2$, iso-octane combustion is slow at engine-like conditions. Splitter [11] has also found that in gasoline/diesel RCCI combustion with premixed gasoline equivalence ratios below approximately 0.22 , combustion mainly involves the direct injected diesel fuel and thus results in high UHC and CO emissions. As the premixed equivalence ratio was below 0.3 at the simulated case. And most of diesel was injected into the piston bowl, thus resulted in lower equivalence ratio and reactivity of mixtures in the cylinder center and squish regions. Additionally the evaporation of ethanol reduced the mixture temperature. As the reaction zone proceeded toward the cylinder center and cylinder wall after ignition, local extinction was prone to happen in these regions due to the lower reactivity and equivalence ratio of mixtures. Thus higher UHC and CO emissions formed in these regions. Moreover, the lower wall temperature near the crevice regions also resulted in quenching of the mixtures.

The formation mechanisms of UHC and $\mathrm{CO}$ emissions are different for fuel lean mixture combustion. UHC is the product of fuel decomposition during low temperature reactions, while $\mathrm{CO}$ is the product of further oxidation of UHC at higher temperature. As the reaction zone proceeded from the bowl lip toward the cylinder center, the peripheral area of the cylinder center was relatively closer to the diesel spray and the gas temperature was relatively higher. Thus UHC in the peripheral area of cylinder center was further oxidized due to relatively higher temperature and resulted in higher $\mathrm{CO}$ mass fraction. The higher UHC and CO emissions are mainly due to the higher enthalpy of vaporization and lower reactivity of ethanol.

\section{Effects of premixed ratios on coefficient of variation (COV)}

Fig. 8 shows the effects of premixed ratio on the variations of IMEP and $Q_{f}$. It can be seen that the variations of IMEP and $Q_{f}$ are gradually increased with the increase of ethanol proportion. The 
variations at the higher load are significantly lower than that of the light load. At the higher load, the cyclic variations of the ethanol/diesel combustion are slightly higher than that of neat diesel operation. The variations of IMEP and $Q_{f}$ have similar magnitudes and trends over the premixed ratio sweep. The IMEP of each cycle is mainly determined by $Q_{f}$ and the combustion phasing. Since the STD of combustion phasing at each operation case is maintained in a small range, the higher IMEP variations are mainly caused by the cycle fluctuations of accumulated heat release. The higher cycle fluctuation of accumulated heat release indicates the higher cycle fluctuations of UHC and CO emissions. It means that with the fluctuations in the mixture composition, initial temperature or pressure, the UHC and CO emissions of each engine cycle show large variations.

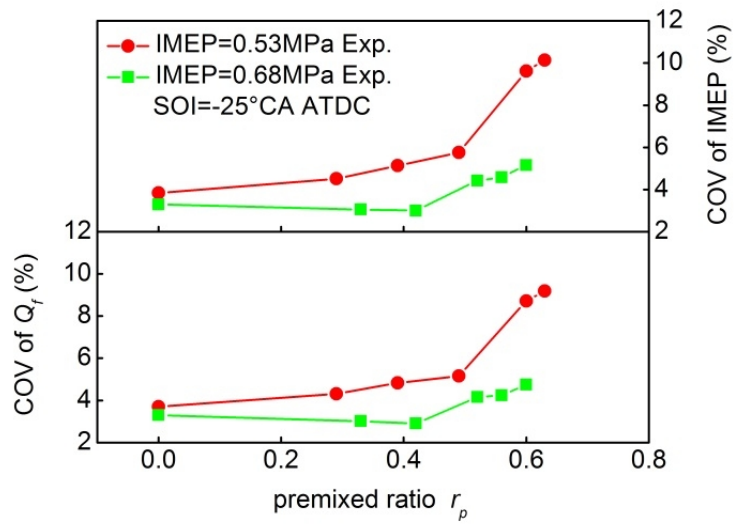

Fig.8. Effects of premixed ratios on IMEP and accumulated heat release variations.

\section{Conclusions}

(1) The experimental results show that the ethanol/diesel dual-fuel combustion can achieve lower soot and NOx emissions, while UHC and CO emissions are higher.

(2) Simulated results show that under the lower load, higher UHC and CO emissions are observed in the cylinder center as well as crevice regions due to the lower reactivity of ethanol.

(3) The ethanol/diesel operation exhibits larger cyclic variations than neat diesel operation, which is mainly due to the lower reactivity of ethanol.

\section{References}

[1] Hwang, W., Dec, J., and Sjöberg, M., "Fuel Stratification for Low-Load HCCI Combustion: Performance \& Fuel-PLIF Measurements," SAE Technical Paper 2007-01-4130, 2007, doi:10.4271/2007-01-4130.

[2] Hashimoto, K., "Effect of Ethanol on the HCCI Combustion," SAE Technical Paper 2007-01-2038, 2007, doi:10.4271/2007-01-2038.

[3] Koci, C., Ra, Y., Krieger, R., Andrie, M. et al., "Detailed Unburned Hydrocarbon Investigations in a Highly-Dilute Diesel Low Temperature Combustion Regime," SAE Int. J. Engines 2(1):858-879, 2009, doi:10.4271/2009-01-0928.

[4] Reitz R, Duraisamy G. Review of high efficiency and clean reactivity controlled compression ignition (RCCI) combustion in internal combustion engines[J]. Progress in Energy and Combustion Science, 2015: 12-71.

[5] Chao, Y., et al., Comparative study on Gasoline Homogeneous Charge Induced Ignition (HCII) by diesel and Gasoline/Diesel Blend Fuels (GDBF) combustion. FUEL, 2013. 106: p. 470-477

[6] Yang B, Yao M, Cheng W K, et al. Experimental and numerical study on different dual-fuel combustion modes fuelled with gasoline and diesel[J]. Applied Energy, 2014, 113(6):722-733. 
[7] Kokjohn, S.L., and Reitz, R.D., Characterization of Dual-Fuel PCCI Combustion in a Light-Duty Engine, 20th International Multidimensional Engine Modeling User's Group Meeting, Detroit, MI, April 12, 2010

[8] Curran, S., Hanson, R., and Wagner, R., "Effect of E85 on RCCI Performance and Emissions on a Multi-Cylinder Light-Duty Diesel Engine," SAE Technical Paper 2012-01-0376, 2012, doi:10.4271/2012-01-0376.

[9] Splitter, D., Wissink, M., DelVescovo, D., and Reitz, R., "RCCI Engine Operation Towards 60\% Thermal Efficiency," SAE Technical Paper 2013-01-0279, 2013, doi:10.4271/2013-01-0279.

[10] Kokjohn S L. Reactivity controlled compression ignition (RCCI) combustion[D]. THE UNIVERSITY OF WISCONSIN-MADISON, 2012.

[11] Splitter, D., Hanson, R., Kokjohn, S., Wissink, M. et al., "Injection Effects in Low Load RCCI Dual-Fuel Combustion," SAE Technical Paper 2011-24-0047, 2011, doi:10.4271/2011-24-0047.

[12] Splitter, D., Hanson, R., Kokjohn, S., and Reitz, R., "Reactivity Controlled Compression Ignition (RCCI) Heavy-Duty Engine Operation at Mid-and High-Loads with Conventional and Alternative Fuels," SAE Technical Paper 2011-01-0363, 2011, doi:10.4271/2011-01-0363.

[13] Qian Y, Wang X, Zhu L, et al. Experimental studies on combustion and emissions of RCCI (reactivity controlled compression ignition) with gasoline/n-heptane and ethanol/n-heptane as fuels[J]. Energy, 2015, 88:584-594.

[14] Sarjovaara T, Larmi M. Dual fuel diesel combustion with an E85 ethanol/gasoline blend[J]. Fuel, 2015: 704-714.

[15]Jia M, Dempsey A B, Wang $\mathrm{H}$, et al. Numerical simulation of cyclic variability in reactivity-controlled compression ignition combustion with a focus on the initial temperature at intake valve closing[J]. International Journal of Engine Research, 2015, 16(3):441-460.

[16] Wang Y, Xiao F, Zhao Y, et al. Study on cycle-by-cycle variations in a diesel engine with dimethyl ether as port premixing fuel[J]. Applied Energy, 2015, 143:58-70.

[17] Wang Q, Wang B, Yao C, et al. Study on cyclic variability of dual fuel combustion in a methanol fumigated diesel engine[J]. Fuel, 2015, 164(2016):99-109.

[18]Kong S C, Sun Y, Rietz R D. Modeling Diesel Spray Flame Liftoff, Sooting Tendency, and NOx Emissions Using Detailed Chemistry With Phenomenological Soot Model[J]. Journal of Engineering for Gas Turbines \& Power, 2007, 129(129):245-251.

[19] Walton S M, He X, Zigler B T, et al. An experimental investigation of iso-octane ignition phenomena[J]. Combustion \& Flame, 2007, 150(3):246-262.

[20]Curran H J, Gaffuri P, Pitz W J, et al. A comprehensive modeling study of iso-octane oxidation[J]. Combustion \& Flame, 2002, 129(3):253-280. 